\title{
NEONATAL ASCITES ASSOCIATED WITH URETHRAL OBSTRUCTION
}

\author{
BY \\ N. E. FRANCE and E. H. BACK \\ From the Queen Elizabeth Hospital for Children, London
}

(RECEIVED FOR PUBLICATION JUNE 18, 1954)

The end of the nineteenth century saw the beginning of a gradual change in the study of the pathology of the foetus and the newborn infant, largely as a result of the work of Ballantyne in Edinburgh. The interest in the examination of grossly deformed monsters was already giving way to the study of foetal conditions which were compatible with life. At this time Fordyce (1894) reviewed 63 cases of foetal ascites, including one case of his own, and showed that, although ascites was frequently associated with gross congenital anomalies, it also occurred with relatively minor evidence of disease in other organs. It remained for Dorland (1919) to distinguish true ascites from other conditions giving rise to marked abdominal enlargement at birth, amongst which he included distension of the urinary bladder, generalized anasarca, congenital polycystic kidneys, cystic degeneration of the liver and fluid distension of the genital tract.

We have been able to find records of 103 cases of foetal ascites in the literature, a number of which showed gross abnormalities of the urogenital or alimentary systems, while others showed only hypertrophy and dilatation of the urinary tract with or without a demonstrable urethral obstruction. A variety of conditions was found in the remaining cases, the most common being chronic peritonitis, usually of obscure origin (Hoffman, Sternberg and Rascoff, 1951); syphilitic hepatitis, cirrhosis of the liver, obstruction of the portal vein and cardiac failure were rare causes of ascites.

The present cases both had urethral obstruction in the absence of other gross anatomical abnormalities.

\section{Case Reports}

Case 1. K.C., a boy, aged $6 \frac{1}{2}$ weeks, was the fourth child of a 37-year-old mother. Pregnancy and labour were normal, and the mother's Kahn reaction was negative. His birth weight was $5 \mathrm{lb} .12 \mathrm{oz}$. $(2,600 \mathrm{~g}$.). He was an obvious mongol; slight abdominal distension which was noted at birth persisted during the neonatal period. He gained weight slowly and for $\mathbf{4 8}$ hours before admission to hospital at the age of $4 \frac{1}{2}$ weeks he had about eight watery stools daily and vomited occasionally.

On examination there was marked abdominal distension, especially of the upper abdomen where there were dilated abdominal veins; there was a small umbilical hernia and bilateral inguinal herniae. Shifting dullness was demonstrated in the abdomen but no masses were palpable. The urine was normal and contained $2 \mathrm{~g}$. chlorides per litre. The baby was noticed to be passing normal amounts of urine although these were not measured.

He was treated with oral fluids for gastro-enteritis but the stools remained frequent although there was no further vomiting. A diagnostic abdominal tap produced clear, straw-coloured fluid containing $\mathbf{4 0}$ cells per c.mm., mostly lymphocytes; it contained $130 \mathrm{mg}$. of protein per $100 \mathrm{ml}$. The following day $20 \mathrm{oz}$. (568 ml.) of similar fluid were removed by paracentesis; subsequent palpation revealed no enlargement of liver or spleen and no masses were felt. The ascites rapidly accumulated and 10 days later a further $30 \mathrm{oz}$. (852 ml.) of fluid were removed. The fluid had a specific gravity of 1010 and contained 126 cells per c.mm. (88\% lymphocytes); the protein content was $500 \mathrm{mg}$. per $100 \mathrm{ml}$. and urea $40 \mathrm{mg}$. per $100 \mathrm{ml}$. The blood urea was $44 \mathrm{mg}$. per $100 \mathrm{ml}$. The baby's condition steadily deteriorated and he died four days after the last abdominal tap with a provisional clinical diagnosis of portal hypertension.

NeCropsy Findings. The body was that of a somewhat emaciated male infant weighing 2,690 g. ( $5 \mathrm{lb}$. $15 \mathrm{oz}$.) and measuring $47 \mathrm{~cm}$. in length. The face, hands and feet showed mongolian features. The abdomen was markedly distended with a circumference of $37.5 \mathrm{~cm}$. (cf. circumference of thorax, $29 \mathrm{~cm}$.). There were bilateral reducible inguinal herniae and a small umbilical hernia. Both testes were palpable in the inguinal canals.

The peritoneal cavity contained about $500 \mathrm{ml}$. of clear, pale yellow fluid. The viscera were normally arranged and the peritoneum was not inflamed.

Both kidneys (Fig. 1) were moderately hydronephrotic, the renal tissue having a thickness of 3 to $6 \mathrm{~mm}$. and showing fairly clear differentiation into cortex and medulla. Near the upper pole of the right kidney was a small cyst, $3 \mathrm{~mm}$. in diameter, which contained a little clear fluid.

The ureters were dilated, tortuous and hypertrophied. Each had a diameter of 6 to $8 \mathrm{~mm}$.

The bladder contained a little pale urine. Anteriorly 


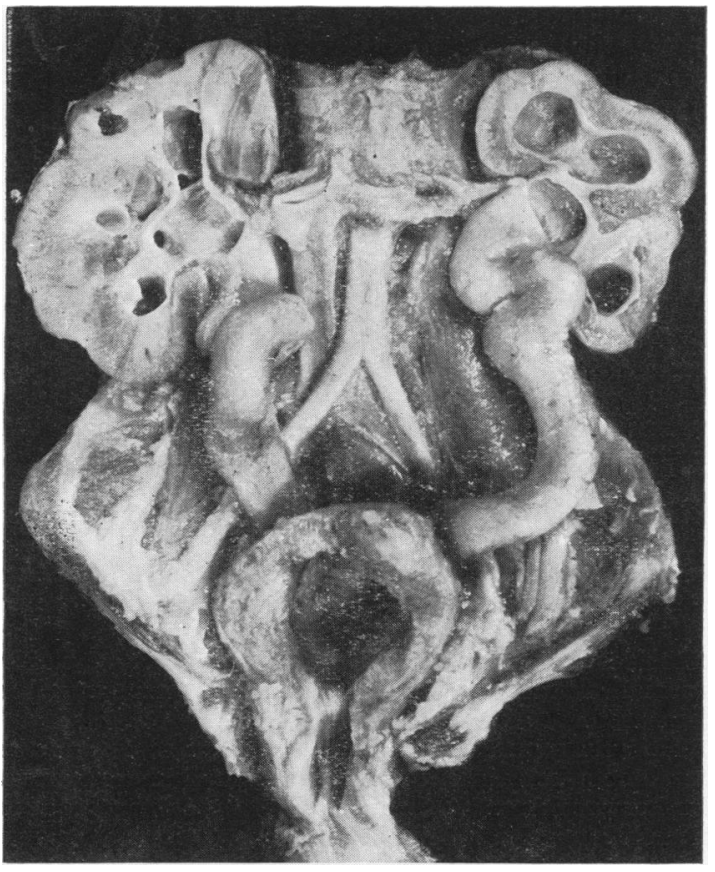

FIG. 1.-Urinary tract of Case 1 showing urethral valve, vesical hypertrophy, and dilatation of ureters and pelves.

and laterally its wall was 5 to $6 \mathrm{~mm}$. thick, mainly the result of muscular hypertrophy although the mucous membrane was slightly thickened and haemorrhagic. In the midline posteriorly the bladder wall was of paper thinness over an area measuring $1.6 \times 1.3 \mathrm{~cm}$. which contained no demonstrable muscle and appeared to be formed mainly from peritoneum. At the apex of the bladder was a small urachal cyst measuring $1.0 \times 0.6 \mathrm{~cm}$.

The posterior urethra was dilated and hypertrophied. The verumontanum was prominent and attached to its lower end were two folds of mucous membrane forming a typical urethral valve.

Apart from patchy collapse of both lungs posteriorly, all other organs were normal.

Microscopical Examination. The left kidney showed distortion of the cortex by scattered small cystic spaces lined by flattened epithelium. These were separated by renal tissue in which tubules were relatively scanty, glomeruli were of normal infantile type and packed closely together, and there was a considerable increase of interstitial tissue. The right kidney was normal.

Section through the greater part of the bladder showed marked muscular hypertrophy with a normal mucosa covered by transitional epithelium. Posteriorly, however, the muscle rapidly thinned and then stopped abruptly leaving areas where the wall was composed of a little loose connective tissue covered by a single layer of flattened epithelium (Fig. 2).
Both lungs showed extensive collapse with a number of small pneumonic foci.

All other organs were normal.

Case 2. D.R., a boy, aged 11 weeks, was delivered at $\overrightarrow{\vec{F}}$ home by vertex presentation in the thirty-fourth week of $\vec{\oplus}$ pregnancy. Delivering the abdomen was difficult. The $\bar{O}$ birth weight was estimated at between 4 and $5 \mathrm{lb}$. As no urine was passed during the first 24 hours of life, he was admitted to hospital. There was marked abdominal distension and the abdomen was tympanitic above the umbilicus and dull to percussion below it. There was a hydrocoele of the left scrotum. The blood urea concentration was $50 \mathrm{mg}$. per $100 \mathrm{ml}$.

A radiograph showed a large, dense opacity in the lower abdomen displacing the intestine upwards. Under general anaesthesia the prepuce was slit dorsally and a fine bicoudé catheter passed per urethram. During the next 24 hours $2 \frac{1}{2} \mathrm{oz}$. $(71 \mathrm{ml}$.) of urine drained through the catheter. The abdominal distension remained, dullness to percussion appeared in both flanks, and the abdominal wall became oedematous, so $5 \mathrm{ml}$. 'diodone' was injected $\infty$ through the catheter, and a radiograph showed it con- $v$ centrated in a small bladder and less concentrated behind of the bladder. These findings suggested rupture of the bladder (Dr. C. J. Hodson). Laparotomy (performed by Mr. V. A. J. Swain) at the age of 48 hours showed

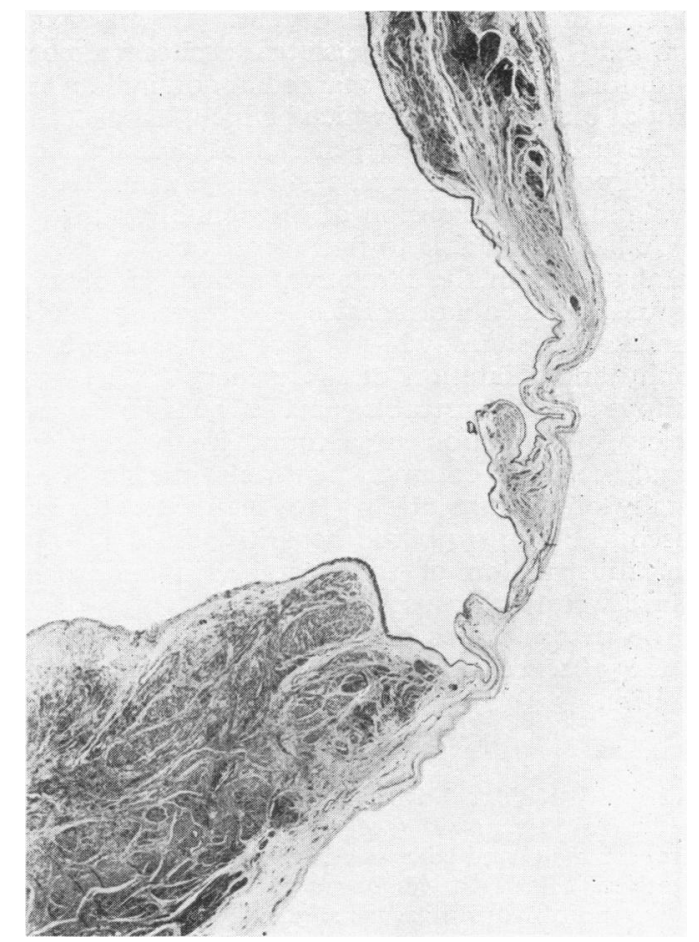

FIG. 2.-Photomicrograph of bladder wall (Case 1) showing localized absence of muscular coat $(\times 11)$. 
much clear, yellow fluid in the peritoneal cavity; the bladder was small and thick walled and there was a hole in its fundus where it was adherent to a loop of small intestine. Both ureters were dilated and the kidneys appeared normal. The hole in the bladder was repaired and a suprapubic cystostomy performed.

Intravenous fluids were given for 36 hours after operation and recovery was satisfactory. The urine drained well through the cystostomy tube and contained a trace of protein and a little blood.

At the age of 10 days the abdomen became distended again, severe vomiting began, and drainage through the suprapubic catheter ceased. As ascites was again evident, tubes were inserted through each flank into the peritoneal cavity under general anaesthesia and much clear yellow fluid escaped on both sides and continued to flow satisfactorily for 24 hours. Abdominal paracentesis on the twelfth and thirteenth days of life produced about $40 \mathrm{ml}$. of fluid on each occasion.

At 13 days urine began to drain through the suprapubic tube and thereafter the infant's condition steadily improved and he gained weight despite a period of paralytic ileus at the age of 20 days and the development of anaemia requiring blood transfusion. The blood urea level, which had risen to $102 \mathrm{mg}$. on the sixth day of life, fell to $29 \mathrm{mg}$. per $100 \mathrm{ml}$. at 27 days. The urine was kept alkaline with potassium citrate and was not infected; it always contained varying amounts of protein with a few pus cells. The measured urinary output was about 9 oz. (256 ml.) daily. The serum electrolyte levels were essentially normal throughout.

At 5 weeks of age the baby had a short episode of diarrhoea during which a specific Esch. coli was isolated from the stools, but the infection rapidly responded to aureomycin.

Despite his well-being the blood urea level was rising and had reached $112 \mathrm{mg}$. by the age of 7 weeks. At 8 weeks the suprapubic tube blocked; drainage was re-established but the catheter slipped out a week later and when re-introduced did not drain any urine. Diodone injected into the catheter showed that the dye passed into the small intestine. The blood urea level had increased to $221 \mathrm{mg}$. per $100 \mathrm{ml}$. Ten days later the baby passed no urine for five days and two days after the flow of urine had begun again spontaneously he died suddenly.

NECROPSY FINDINGS. The body was that of a male infant weighing 3,080 g. (6 lb. 13 oz.) and measuring $50 \mathrm{~cm}$. in length. The abdomen was distended and tympanitic with a protuberant umbilicus and a circumference of $36 \mathrm{~cm}$. (cf. circumference of thorax, $32 \mathrm{~cm}$.). An old right paramedian operation scar continued at its lower end into a cystotomy wound from which a little pus exuded. Both testes were in the scrotum.

The peritoneal cavity was largely obliterated by fine fibrous adhesions binding the loops of small intestine together but it also contained about $20 \mathrm{ml}$. of pale clear fluid.

Both kidneys showed considerable reduction in the thickness of the renal tissue with poor differentiation between cortex and medulla. There were occasional small irregular cavities up to $1.5 \mathrm{~mm}$. in diameter in the medulla. The pelves were moderately dilated but had a smooth lining. The left kidney was about twice as large as the right kidney.

The ureters were dilated to 6-7 $\mathrm{mm}$. in diameter, tortuous and hypertrophied.

The bladder was contracted and had a muscular wall about $1 \mathrm{~cm}$. thick with mild hyperplasia of the mucosa. In the fundus a small hole measuring $2 \times 1 \mathrm{~mm}$. had been partially closed by a catgut suture but allowed communication between the bladder and a smooth-walled, cystic space, $1 \mathrm{~cm}$. in diameter. The latter was firmly adherent to a loop of ileum and was surrounded by fibrous adhesions. No leakage into the general peritoneal cavity or the small intestine from either the bladder or the cyst could be demonstrated.

The posterior urethra was dilated and hypertrophied. The verumontanum was prominent and continued inferiorly into two prominent folds of mucosa running downwards and around the urethra forming a typical congenital urethral valve.

All other organs appeared normal.

Microscopical ExAMination. Both kidneys showed much interstitial fibrosis with infiltration with lymphocytes, plasma cells, and occasional eosinophilic polymorphs. The glomeruli were reduced in number and many were fibrosed or hyalinized. Small cysts lined with flattened epithelium were in the medulla. There was no evidence of pyelonephritis.

The 'cyst' communicating with the bladder was lined with lymphocytes, plasma cells, and phagocytes, and showed a little smooth muscle in its otherwise fibrous wall.

All other organs were normal.

\section{Discussion}

Twenty-two cases of undoubted ascites associated with dilatation of the urinary tract have been described in the literature; the majority were stillborn or died soon after birth. In one case (Hicks, 1864) both ureters were occluded in their lower thirds although the bladder contained a little urine and the urethra was apparently not examined; Bruce (1870) found an anatomically patent urethra although the right ureter did not communicate with the bladder; Moreau's case (1828) showed dilatation of the bladder but he did not describe the urethra, whereas Edgecombe (1930) found no urinary obstruction apart from phimosis.

An organic urethral obstruction was demonstrated in the remaining 18 cases. In four infants both urethra and anus were imperforate (Duncan, 1870; Gilles, Roques and Lefèvre, 1914; Hunter, 1932; Gercken and Knepper, 1937), the rectum or sigmoid colon ending blindly behind a grossly dilated bladder or communicating with it through a persistent cloaca.

In 14 children there was urethral obstruction with varying degrees of urinary tract dilatation but no abnormalities of the alimentary or other systems. 
Since the majority of the earlier cases were recorded because of the obstetrical problems arising from the foetal abdominal distension, a detailed anatomical description of the urinary tract was frequently lacking and the sites and types of urethral obstruction poorly described. Some had atresia of the urethra (King, 1837; Williams and Galabin, 1878); others a membranous septum (Ballantyne, 1893). Porak (1895) described a typical urethral valve, while others mentioned only the presence of a stricture usually in the posterior urethra (Eden, 1904; Luker, 1913). The bladder was invariably distended and often hypertrophied and megalo-ureters usually coexisted. Hydronephrosis was often absent (Eden, 1904; Luker, 1913), while hypoplasia of one kidney (Williams and Galabin, 1878) or polycystic renal disease (Porak, 1895) was sometimes seen. Magyar (1946) described the presence of a patent urachus.

The most recently reported cases have shown congenital urethral valves. Parrott (1951) described a 28-day-old boy who died with grossly infected kidneys, and one of Lord's cases (1953) survived for five weeks. James and Davis (1952) described a boy who was operated on when 3 weeks old; a urethral obstruction was broken down and the child was well at 8 months of age.

The relationship between ascites and urethral obstruction has been discussed by Lord (1953) who stated that leakage or transudation of urine from the bladder, ureters, or kidneys appears to be the most plausible cause of hydroperitoneum. Reliable data pointing to such a pathogenesis, however, are not generally available. Actual perforation of the bladder was described by King (1937) in a foetus of four months' gestation who had complete atresia of the posterior urethra with marked dilatation and hypertrophy of the bladder, bilateral megalo-ureters, and small kidneys. A hole $1 \cdot 3 \mathrm{~cm}$. long was situated just behind the summit of the bladder and allowed a free flow of urine into the peritoneal cavity, the fluid in which contained fibrin. Case 2 showed a similar perforation of the bladder; although it could be argued that this was caused by preliminary catheterization, the adhesions around the rupture suggest that the lesion was of longer standing.

Duncan (1870) described a stillborn infant with atresia of the urethra $5 \mathrm{~cm}$. below the neck of the bladder with a communication between the large intestine and bladder. While the muscular coat of the lower two-thirds of the bladder was about $1 \mathrm{~cm}$. thick, in its upper third the vesical wall consisted of peritoneum and mucous membrane only.
This was a lesion similar although more extensive to that found in Case 1, and strongly suggests the possibility that urine may have passed directly across this thin membrane and accumulated in the peritoneal cavity.

In no case has obvious leakage from the kidneys been demonstrated, although thin-walled renal cysts are frequent (Lord, 1953), and Porak (1895) described one very voluminous cyst in the left kidney of his case. Baar (1954) has recently seen a child who lived only two minutes in whom the peritoneal cavity contained about $400 \mathrm{ml}$. of fluid; the bladder was hypertrophied and the urinary tract dilated without any organic urethral obstruction. A thinwalled cyst about $6 \mathrm{~cm}$. in diameter was situated just beneath the capsule on the anterior surface of the right kidney. It is possible that fluid may transude from such a cyst into the peritoneal cavity without actual rupture.

\section{Summary}

Two male infants with congenital urethral valves and ascites occurring in the neonatal period are reported. In one case muscle in the wall of the bladder was partially lacking, in the other the bladder ruptured.

It is suggested that in the presence of urethral obstruction, ascites is due to the accumulation of urine in the peritoneal cavity following leakage of $\overrightarrow{0}$ transudation from the urinary tract.

We wish to thank Dr. J. N. O'Reilly and Dr. R. H Dobbs for permission to publish the clinical details of these cases, Dr. C. J. Hodson for his reports on the radiological findings, and Mrs. F. M. Byron for her technical assistance.

\section{REFERENCES}

Baar, H. S. (1954). Personal communication. Ballantyne, J. W. (1893). Edinb. Hosp. Rep., 1, 612.

Dorland, W. A. N. (1919). Amer.J. Obstet., 79, 474.

Duncan, M. (1870). Edinb. med. J., 16, 163.

Eden, T. W. (1904). Trans. Obstet. Soc. Lond. (1903), 45, 45

Edgecombe, K. (1930). J. Obstet. Gynaec. Brit. Emp., 37, 832.

Fordyce, W. (1894). Teratologia, 1, 61, 143.

Gercken, R and Knepper, R. (1937). Zbl. Gynäk., 61, 710.

Gilles, Roques and Lefève (1914). Bull. Soc. Obstet. Gynec., Paris Gilles, Roques

Hicks, J. B. (1864). Trans. Obstet. Soc., Lond. (1863), 5, 285.

Hoffman C. Aternoers. J. Dis. Child., 82, 28 .

Hunter, R. H. (1932). Lancet, 2, 999.

James, U. and Davis, J. A. (1952). Proc. roy. Soc. Med., 45, 401.

King, T. W. (1837). Guy's Hosp. Rep., 2 (1st series), 508

Lord, J. M. (1953). Archives of Disease in Childhood, 28, 398.

Luker, S. G. (1913). Lancet, 1, 1309.

Magyar, K. (1946). Gynaecologia, 122, 363.

Moreau (1828). Arch. gén. Méd., 17, 299.

Parrott R. H. (1951). Clin. Proc. Child. Hosp., Wash., 7, 309.

Porak (1895). J. méd. franç., Sér. 2, 7, 392. (1877), 19, 120 . 